\title{
ORCID IN THE OPEN SCIENCE SCENARIO: OPPORTUNITIES FOR ACADEMIC LIBRARIES
}

\section{by Paloma Marín-Arraiza}

\begin{abstract}
The persistent identification of authors and contributors plays a decisive role within the Open Science landscape. The increasing number of published research products and new open publishing models and infrastructures requires author identification which goes beyond fields or infrastructures and guarantees interoperability. $O R C I D$ iD is presented as a persistent identifier for researchers in this context. As information managers and organisers, many academic libraries have taken the lead in offering ORCID-related services and implementing it in their systems. This paper scans the implementation models across Europe and the actions carried out by libraries. Finally, it also depicts perspectives for integration in the Austrian library and research context.
\end{abstract}

Keywords: Open Science; ORCID; persistent identifiers; academic libraries; Austrian perspectives

\section{ORCID IM OPEN SCIENCE-SZENARIO: CHANCEN FÜR WISSENSCHAFTLICHE BIBLIOTHEKEN}

Zusammenfassung: Die persistente Identifikation von Autor_innen und Mitwirkenden spielt eine entscheidende Rolle innerhalb der Open Science-Landschaft. Die zunehmende Anzahl an veröffentlichten Forschungsergebnissen und neuen Open-Publishing-Modellen und -Infrastrukturen erfordert eine Autor_innenidentifikation, die über Bereiche oder Infrastrukturen hinausgeht und Interoperabilität gewährleistet. ORCID iD wird in diesem Zusammenhang als persistenter Identifikator für Forschende präsentiert. Als Informationsmanagerinnen und Organisatorinnen haben viele wissenschaftliche Bibliotheken den Lead übernommen, indem sie ORCID-bezogene Dienstleistungen anbieten und in ihren Systemen implementieren. Dieser Artikel analysiert die europaweiten Implementierungsmodelle und in Bibliotheken durchgeführten Aktivitäten. Abschließend werden auch Perspektiven für die Integration in den österreichischen Bibliotheks- und Forschungskontext dargestellt.

Schlüsselwörter: Open Science; ORCID; persistente Identifikatoren; wissenschaftliche Bibliotheken; österreichische Perspektiven.

DOI: https://doi.org/10.31263/voebm.v72i2.2811 
Dieses Werk ist lizenziert unter einer

Creative-Commons-Lizenz Namensnennung 4.0 International

\section{Contents}

1. Introduction

2. ORCID and its presence in the Open Science landscape

3. Scanning ORCID implementation models in European academic libraries

4. ORCID perspectives in the Austrian research landscape

5. Conclusions

\section{Introduction}

The implementation of Open Science (OS) practices is changing how researchers, funding bodies and governments approach research. Current scientific practices are required to be more transparent, sustainable and collaborative as a way to increase knowledge exchange globally.

The OS movement changes the modus operandi in research tasks, approaching scholarly practices from a perspective of having no enclosing barrier and guaranteeing access to all or nearly all results and actions. One of these tasks is the identification of entities within the research lifecycle (Dappert, Farquhar, Kotarski, \& Hewlett, 2017). Researchers, as creators of content, information and even knowledge, occupy a central role in this lifecycle. Thus, the proper and unique identification of researchers has become a central issue. Due to name similarities or name modifications along the citation process, they often do not receive direct credit for their research (Gasparyan, Yessirkepov, Gerasimov, Kostyukova, \& Kitas, 2016; Reimer, 2015). Therefore, there is a need for persistent identifiers for researchers, such as ORCID iD.

Academic libraries can support researchers throughout the entire research process, act as assessors and data and publication managers (Ayris et al., 2018; Ayris \& Ignat, 2018; Tenopir, Sandusky, Allard, \& Birch, 2013), and join forces to support infrastructure development and management (Haak et al., 2012). This includes helping researcher to manage their personal identifiers.

Methodologically, this paper uses qualitative and exploratory methods divided into two procedures. The first procedure is a literature review performed via two academic databases (Scopus and Dimensions) and an academic web search engine (Google Scholar) with the keywords 'ORCID', 
'Open Science' and 'Academic Libraries' and their Boolean combination with the 'and' operator. The second procedure was a scanning of already existing ORCID implementation models and services in European academic libraries. The sample of academic libraries was obtained from the ORCID member database', selecting first 'consortia members' and then 'all members' and applying the filter 'research institute'. The information available about the institution was collected from the member database itself and the corresponding library website.

In this context, this paper addresses how ORCID fits in the OS scenario, how institutions implement ORCID and the role of libraries in this implementation and the current state of ORCID in Austria, as well as the perspectives for Austrian academic libraries.

This paper is organised as follows. After this first section, which introduced the paper, methodology and outline, the second section presents ORCID, compares it with other identifiers used in scholarly communication and describes its contextualisation in the OS scenario. The third section details the implementation of ORCID in European academic libraries, focusing on the implementations of consortia led by libraries. The fourth section discusses the state of ORCID in Austria and perspectives for Austrian academic libraries. The fifth section concludes the paper.

\section{ORCID and its presence in the Open Science landscape}

Several publishers, publishing platforms, libraries and other organisations have developed identifiers to distinguish persons and link them with their works. Some of the most well-known and broadly-used identifiers in scholarly communication and their main characteristics are summarised in Table 1.

Some identifiers are discipline- or platform-related (e.g. arXiv Author ID) or provided automatically by a vendor system (e.g. ResearcherID or Scopus Author ID), and are therefore not openly available for all researchers worldwide, which considerably reduces their uptake. In other cases, identifiers are not user-driven, meaning that users are not able to control the content or information related to their identifier (e.g. GND or ISNI). To overcome these restrictions on both access to the identifier and modification of the attached information, the ORCID iD appeared in 2012.

The ORCID iD is a persistent identifier consisting of an alphanumeric code of 16 digits that follows the ISO standard ISO $27729^{2}$. Apart from the persistent identification, it refers to a platform, the ORCID Record, showing the researcher's affiliations, works, memberships and peer review activities. 


\begin{tabular}{|c|c|c|}
\hline $\begin{array}{c}\text { Person } \\
\text { identifiers }\end{array}$ & $\begin{array}{l}\text { Date of } \\
\text { release }\end{array}$ & Main characteristics \\
\hline arXiv Author ID & 2005 & $\begin{array}{l}\text { - Discipline-specific for arXiv users } \\
\text { - Disambiguation of papers within the arXiv repository } \\
\text { - Developed by Cornell University Library } \\
\text { - OAI-PMH provided }\end{array}$ \\
\hline AuthorClaim & 1992 & $\begin{array}{l}\text { - Generation of author output profiles } \\
\text { - Disambiguation of authors and profiles across disciplines } \\
\text { - Interaction with publishers and repositories such as Crossref, } \\
\text { arXiv or PubMed } \\
\text { - Data available under CCO licence } \\
\text { - Example: use case of linked open data in libraries }\end{array}$ \\
\hline GND & 2012 & $\begin{array}{l}\text { - In accordance with Resource Description and Access (RDA) } \\
\text { norms } \\
\text { - Mainly used in German-speaking Europe and for library } \\
\text { classification } \\
\text { - Data available under CC0 licence } \\
\text { - The entity type 'p' covers person identification }\end{array}$ \\
\hline ISNI & 2012 & $\begin{array}{l}\text { - Identifier for contributors to media content } \\
\text { - Follows the ISO standard ISO } 27729 \\
\text { - Used in library catalogues } \\
\text { - Interoperable with other systems } \\
\text { - Not user driven }\end{array}$ \\
\hline ORCID iD & 2012 & $\begin{array}{l}\text { - User-driven identifier } \\
\text { - Users handle records creation, management and privacy control } \\
\text { - Allows import from various systems (Scopus, ResearcherID, } \\
\text { DataCite, Redalyc, BASE...) } \\
\text { - Follows the ISO Standard ISO } 27729 \text { and the ISO/IEC } \\
\text { 7064:2003 for the last digit of the code } \\
\text { - Public API provided for data reading } \\
\text { - Update rights (basic and premium API) require membership }\end{array}$ \\
\hline ResearcherID & 2008 & $\begin{array}{l}\text { - Institutions can create identifiers and records } \\
\text { - User-populated records } \\
\text { - Created by Thomson Reuters (now: Clarivate Analytics) and } \\
\text { integrated in their other products (e.g. impact statistics) } \\
\text { - Interoperable with ORCID } \\
\text { - API provided }\end{array}$ \\
\hline Scopus Author ID & 2006 & $\begin{array}{l}\text { - Automatically generated based on author characteristics } \\
\text { (affiliation, discipline...) } \\
\text { - Linked to Elsevier-Scopus publications } \\
\text { - Authors may have multiples profiles (depending on name, } \\
\text { discipline or affiliation) } \\
\text { - Integration with other Elsevier products (e.g. Mendeley) and } \\
\text { external services (e.g. ORCID) } \\
\text { - Extensive API provided }\end{array}$ \\
\hline
\end{tabular}

Tab. 1: Some person identifiers in the scholarly context. Source: Elaborated by the author based on several web sources. 
It is also worth mentioning that ORCID iD should not be understood as an online social network, even though it contributes to the researchers' visibility and digital presence. Despite having some of the characteristics of an online social network (e.g. identification and personal attributes), it lacks the most defining ones, namely the processes of communication and interrelations between individuals and institutions (Rodrigues \& Sant'Ana, 2018). These characteristics, however, are partially present in profiles such as Mendeley and completely present in ResearchGate or Academia.edu, which are indeed an academic online social network.

One of the OS movement's goals is the global visibility of research. As a way to support that, the ORCID schema is available in different languages, in an attempt to reach non-Anglophone countries and researchers (Gasparyan, Akazhanov, Voronov, \& Kitas, 2014). The language adaptation, together with the user-driven approach and the interoperability with different publication platforms worldwide, turn ORCID iD into a transparent way to assert researchers identity (García-Peñalvo, 2018). These characteristics warrant its increasing uptake and the recently reached 6 million of ORCID iDs.

Another goal of the OS movement, according to the FOSTER Open Science Project ${ }^{3}$, is to enable the redistribution of research results and other research processes, independently of their nature and discipline. This goal involves the recognition of research products beyond textual publications (Klein \& Van de Sompel, 2017; Piwowar, 2013) and requires their inclusion in the researchers' production lists.

As a way to accomplish this goal, the ORCID Record presents four categories - publication, conference, intellectual property and other - which cover all possible scholarly outputs or research-related activities. Works can be added manually or imported automatically from the publication platforms, with which ORCID interoperates. These platforms include Crossref ${ }^{4}$, DataCite $^{5}$, BASE $^{6}$, Redalyc ${ }^{7}$ and Europe PubMed Central ${ }^{8}$, among others.

Moreover, well-managed ORCID records can be key elements in assessing data management and research data quality, since they link researchers and their contributions unambiguously. One example can be found in Portugal, where ORCID is used as a central hub to guarantee data consistency when synchronising the national CRIS Systems (Lopes, 2019). ORCID iDs are also a helpful starting point for bibliometric studies and co-authorship analyses (Youtie, Carley, Porter \& Shapira, 2017), and connect authors, their research and track citations easily, as performed by the Portuguese Foundation for Science and Technology (FCT) in 2013 (FCT, 2013). According to Klein and Van de Sompel (2017), ORCID iDs and the ORCID data 
could even serve as a base for discovering scholarly objects excluded from the current archival system. This is also the aim of projects addressing the inclusion of grey literature in scholarly communication cycles.

Having described the intersection between ORCID and the OS movement, the focus now lies on one of the main actors when it comes to scholarly communication: academic libraries.

\section{Scanning ORCID implementation models in European academic libraries}

The roles of academic libraries as OS enablers have been pointed out by several authors (Ayris, Bernal et al., 2018; Ayris \& Ignat, 2018; Ogungbeni, Obiamalu, Ssemambo, \& Bazibu, 2018), whether for providing an appropriate research infrastructure, fostering OS practices, offering support for researchers or including data management services (Horstmann \& Brase, 2016; Rice \& Southall, 2016; Tenopir, Sandusky, Allard, \& Birch, 2014). In this respect, libraries have been actively involved in the development of PID services, including ORCID and its institutional engagement (Kraft, Dreyer, Löwe \& Ziedorn, 2017; Akers, Sarkozy, Wu, \& Slyman, 2016; De-Castro, 2015; Reimer, 2015).

According to Akers et al. (2016), libraries can take on the following tasks ${ }^{9}$ to promote ORCID: (1) Raise awareness of ORCID iDs; (2) help researchers register for ORCID iDs and populate ORCID records ${ }^{10} ;$ (3) integrate ORCID iDs into institutional repositories and university systems, (4) teach researchers to use their ORCID iDs.

From an organisational perspective, tasks (1), (2) and (4) imply developing workshops about ORCID and the use of ORCID iD as part of the continuing education programmes offered by the library. These workshops should address the creation of an $\mathrm{iD}$, as well as how to import (manually or automatically) works, funding and peer-reviewed activities to the record. Libraries can also include information about ORCID in their publication support and personal advice or specific activities such as Open Access Weeks. Further channels to promote ORCID are library websites, blogs or social networks. From a technical perspective, task (3) requires an ORCID membership to access the ORCID application programming interface (API) and use ORCID features. Through the ORCID API, institutional repositories and university systems can synchronise the data exchange with ORCID. The API also allows institutions to standardise their employees' information contained in the records. Several systems integrate and support ORCID in their workflows. For instance, DSpace CRIS, VIVO or PURE as research 
information management systems, Open Journal Systems (OJS) as publishing systems, or DSpace or EPrints as repository systems. Libraries might not always have enough technical resources to implement ORCID in their systems; therefore, teaming up with IT departments is a solution to consider in these cases. Libraries can then keep a coordinating role and support IT departments to fulfil best practices ${ }^{11}$ for ORCID implementations.

Apart from the above, libraries can use ORCID iDs and their attached information to enhance library metadata, online catalogues (OPACs) and discovery services, for example analysing the integration of ORCID in Resource Access Description (RDA) or MARC21.

To go deeper into the activities carried out by European academic libraries around ORCID and how they implement it, libraries were selected from the data available in the ORCID member database. More details about the activities of each library were then obtained directly from its website. In the case of consortia, whose lead organisation was not a research institute but a funding body - as it happens in the UK, among others - further initiatives within the consortium promoted by libraries were analysed.

At the time of writing this article, twelve European countries ${ }^{12}$ have founded ORCID consortia. Five of them are coordinated by libraries. In Austria, the TU Wien Bibliothek and Vienna University Library lead the consortium; in Denmark, the Aalborg Academic library (previously Denmark's Electronic Research Library); in Germany, the German National Library of Science and Technology (TIB); in Greece, the Hellenic Academic Libraries; and in Portugal, the University of Aveiro (mainly represented by its library). Besides the consortia, ten countries ${ }^{13}$ in Europe have institutional members (research institutions, funding bodies, publishers, among others). Libraries take over the coordinating role in several of these institutions. As is the case, for example, with the library of the Cyprus University of Technology, the Library and Information Centre of the Hungarian Academy of Sciences, the library of the Conseil Européen pour la Recherche Nucléaire (CERN) or the academic libraries in Spain.

It is also worth mentioning that several libraries offer information about ORCID and support for the creation and actualisation of a record, even though the institution is not an ORCID member.

Therefore, it is possible to distinguish two models when engaging with ORCID: the individual and the institutional. The institutional model is supported by single institutions and by groups of institutions forming a consortium. Both imply the individual creation of an ORCID iD. However, the data input, actualisation, standardisation and main actors vary as summarised in the Table 2. 


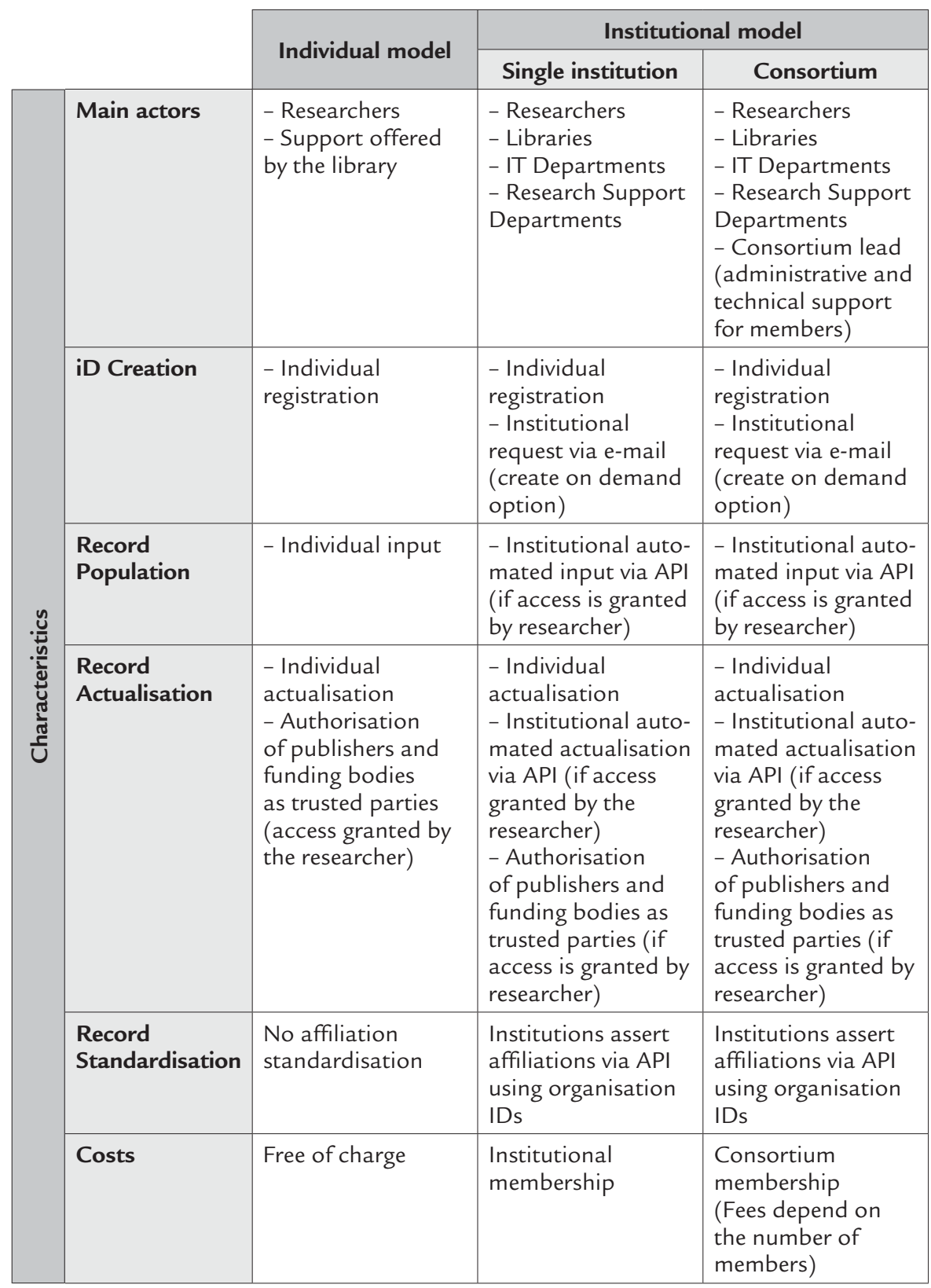

Tab. 2: General comparison between the individual and the institutional model. Source: Elaborated by the author. 
The individual model - without naming it this way - was introduced by Reimer (2016) as a solution for universities that are not in a position to become an institutional member of ORCID, due to lack of personnel and financial resources. The university should encourage faculty, staff and students to register and consider libraries as central agents in promoting and supporting the use of ORCID. Examples of this approach are to find at the university library of the Open University of Catalonia, that embeds ORCID in its 'Information kit for researchers'14 or in the website ${ }^{15}$ of the Documentation Services of the University of Minho (Portugal).

The individual model is more time-consuming for the researcher and less data-driven than the institutional model. The institutional model facilitates appearance in and synchronisation with internal research information systems, albeit with certain costs and a higher institutional IT involvement. It is also possible, and recommended, to carry out an active campaign to encourage the use of ORCID and then automatize some actions (Thomas, Chen, \& Clement, 2015).

If a group of institutions opt for the institutional model forming a consortium, it might follow a centralised or decentralised approach.

The centralised approach involves a project for the whole consortium. For instance, the implementation of ORCID in the Scientific Information System of Andalusia (SICA2) in South Spain (Cámara-Aroca et al., 2015) as part of the activities of the former ORCID Consortium in Andalusia led by the Andalusian Consortium of Academic libraries or the creation of a centralised information hub, as it's the case in the Italian consortium.

The Danish consortium, led by the Aalborg University Library, follows a centralized approach as well. This is, in part, possible, as all institutions in the consortium use PURE as a system. Having unanimity on the use of software facilitates the exchange of information and solutions between the different institutions. A highlighted aspect in Denmark is the need to have a consortium lead integrated into the day-to-day scientific activity and knows its needs (Melchiorsen, 2019).

The decentralised approach involves implementation at the institutional level, with consortium members developing their own help-desks and organisational units. This approach is preferred when the member institutions use different software for their information systems.

A European consortium following this approach is the German consortium. In addition to the activities developed by its forty-nine (49) members, the German consortium also carries out a project funded by the German Research Foundation (Deutsche Forschungsgemeinschaft - DFG) with the active participation of the German National Library ${ }^{16}$. This project has two 
main goals related to scholarly communication: one is the integration of the Bielefeld Academic Search Engine (BASE) within the ORCID network, and the other, the link between ORCID iD and the Integrated Authority File (Gemeinsame Normdatei - GND). The integration with BASE already allows the link between the ORCID Records and the more than 140 million documents available in the database. This integration includes the participation of the Bielefeld University Library, which operates the document database. For its part, the consortium leader, TIB, is working on the implementation of ORCID in VIVO ${ }^{17}$, a linked data-based research information system.

In Portugal, the consortium members and their libraries are more focused on promoting ORCID through training activities, being the FCT the initiator of further technical implementations at the national level. ORCID is used as an identifier when applying for funding and is integrated into the national scientific database, Ciência Vitae. Currently, this foundation is working on the integration of ORCID in RCAAP (Repositório Científico de Acesso Aberto de Portugal, Portuguese for 'Open Access Scientific Repositories of Portugal') ${ }^{18}$, an interface, or entry point, for accessing open access publications distributed by 227 Portuguese repositories.

In the United Kingdom, Belgium and the Netherlands, consortia are not led by libraries, but they have an active pacification of libraries. With ninety-five (95) members, the UK consortium is the largest in Europe, allowing the lead institution, Jisc, to conduct more in-depth studies on the implementation of ORCID and its cost-benefit (Henderson, Johnson, \& Woodward, 2015). Another relevant material, developed with support from the Imperial College London library, is an interactive decision tree ${ }^{19}$ for those organisations thinking of joining ORCID. For information systems, most UK universities opt for EPrints, PURE or Sympletic Elements. An example is the University of Greenwich, which uses EPrints for GALA (Greenwich Academic Literature Archive) ${ }^{20}$, following completely ORCID best practices for integration. GALA is operated by the IT and Library Services of the University of Greenwich.

In Belgium, the Ghent University library has participated in the Belgian adaptation of DMPOnline, DMPbelgium ${ }^{21}$, a tool for creating data management plans. This tool has included ORCID for the identification of authors and the automatic collection of available data about the author. The authors' persistent identification with ORCID contributes to the machine-readability of these data management plans.

In the Netherlands, the Leiden University Library, apart from implementing ORCID in their CRIS System, is planning to include the iD in the 
Leiden Open Variation Database (LOVD) ${ }^{22}$ for the registry as a submitter. LOVD is an open source database that collects and displays variants observations in the DNA sequence; currently, more than one billion.

The situation in Austria, where the consortium also follows a decentralised approach, is described in more detail in the following section.

\section{ORCID perspectives in the Austrian research landscape}

Austria founded its ORCID consortium in January 2019 for a first period of three years after several years of national discussion. Several factors influenced its foundation: the conversations initiated by the Scientometrics Working Group of the University of Vienna ${ }^{23}$, the support and ORCID mandate of the funding body Austrian Science Fund (FWF) and the connections established through the government-cofunded project e-Infrastructures Austria Plus ${ }^{24}$. In May 2018, the University of Natural Resources and Life Sciences (BOKU) in Vienna organised the first ORCID Austria workshop that moved forward the discussions about forming a consortium.

At the time of the workshop, there were around 16,500 ORCID iDs registered with an '. at' e-mail address (Heindl, Hikl, \& Kaier, 2018). In less than a year (May 2019), the number rose to 21,666 (an increase of around $31 \%$ ). These numbers show the increasing uptake of ORCID in Austria, a positive sign for the consortium, which aims to 'establish ORCID iD as the primary unique person identifier for researchers in the Austrian research ecosystem' (Marín-Arraiza \& Gumpenberger, 2019).

Currently (May 2019), the Austrian consortium has eleven member institutions: one funding body and ten universities ${ }^{25}$. The libraries of seven of these institutions are in charge of the coordination of ORCID services within their institution, teaming up with other departments such as research support or IT. Therefore, it is necessary to develop well-defined internal workflows to provide suitable ORCID services for researchers.

In terms of services, four universities (Graz University of Technology, University of Vienna, Montanuniversität Leoben and Technical University of Vienna) have implemented or started implementing ORCID in their systems. The first three universities use PURE from Elsevier as a CRIS (Current Research Information System). Given the extensive use of PURE, the interoperability and full data synchronisation between PURE and ORCID are guaranteed. Outside the Austrian borders, for instance, the Aalborg Academic library in Denmark has completed the integration of its research 
portal with ORCID using PURE. The fourth uses TISS (TU Wien Informations-Systeme \& Services), a self-developed solution, that offers an overview of current teaching and research activities at the university.

Research information systems in Austria are very heterogeneous. Solutions vary from institution to institution and depending on the type of platform (repository, data repository, CRIS, journal system, among others). Phaidra/Fedora (University of Vienna and University of Veterinary Medicine), Visual Library (TU Wien, BOKU, University of Salzburg, and University of Graz) and EPrints (Vienna University of Economics and Business) are the main solutions for repositories among the consortium members. For CRIS, PURE (University of Vienna, Graz University of Technology, Montanuniversität Leoben) or self-developed solutions are preferred. For journal systems, Open Journal Systems (OJS) is the predominant solution. In the case of funding bodies, FWF has chosen Researchfish for their research documentation system, enabling the data flux between this platform and the researcher's ORCID record.

Therefore, the Austrian consortium has opted for a decentralised approach, without a national strategy for the integration with ORCID. However, the consortium leadership provides different channels for communication among members. In the future, this might allow small working groups to cooperate and implement ORCID in a determined way, especially regarding data repositories, as in the case of CKAN, Dataverse or DSpace, or in platforms not based on an ORCID-enabled system ${ }^{26}$.

\section{Conclusions}

ORCID iD as a user-driven personal identifier is here to stay and is supported by research institutions, funding bodies and publishers all over the world. This paper showed its relevance in the OS scenario and compared it with other personal identifiers present in the scholarly communication ecosystem.

Academic libraries have been identified as key actors in this OS scenario, even as enablers of OS practices, as well as in the adaption of ORCID iD as personal identifier. In fact, in Europe, academic libraries are directly involved in the implementation of ORCID. Besides actions to build awareness about the usage of ORCID, libraries adopt a coordinating role and should develop well-defined workflows to establish ORCID services. Researchers should not be forgotten in these workflows and their needs should be and remain in the centre of all services, since their ORCID records should be seen as a way to manage their research activities efficiently. 
In Austria, the uptake of ORCID is increasing continuously (an increment of about $31 \%$ in the last year). Now it is the turn of institutions to integrate ORCID and profit from its use. Consequently, ORCID records can be further used for research assessment activities such as the monitoring of academic production and evaluation processes (within the institution and externally), as already happens in Portugal.

The establishment of small, and possibly open, working groups can also be a path to follow in Austria to increase the interoperability with ORCID, discuss further implementations and exchange ideas for the definition of workflows.

Lic. Paloma Marín-Arraiza, MU ORCID: https://orcid.org/0000-0001-7460-7794 TU Wien (Vienna University of Technology), Library E-Mail: paloma.arraiza@tuwien.ac.at

\section{References}

Akers, K. G., Sarkozy, A., Wu, W., \& Slyman, A. (2016). ORCID Author Identifiers: A Primer for Librarians. Medical Reference Services Quarterly, 35(2), 135-144. https://doi.org/10.1080/02763869.2016.1152139

Ayris, P., Bernal, I., Cavalli, V., Dorch, B., Frey, J., Hallik, M., ... Horstmann, W. (2018). Liber Open Science Roadmap. https://doi.org/10.5281/ zenodo.1303002

Ayris, P., \& Ignat, T. (2018). Defining the role of libraries in the Open Science landscape: a reflection on current European practice. Open Information Science, 2(1), 1-22. https://doi.org/10.1515/opis-2018-0001

Cámara-Aroca, M., Cascajares-Rupérez, M., Franco-Barroso, C., Fernández-Cordero, R., García-Gil, Ma. Á., Morales-Cáceres, Ma. Á., ... Pascual del Pobil Valdenebro, A. (2015). Implantación del identificador ORCID en las universidades andaluzas. Boletín de la Asociación Andaluza de Bibliotecarios, 109, 132-143.

Dappert, A., Farquhar, A., Kotarski, R., \& Hewlett, K. (2017). Connecting the Persistent Identifier Ecosystem: Building the Technical and Human Infrastructure for Open Research. Data Science Journal, 16, 28. https:// doi.org/10.5334/dsj-2017-028

De-Castro, P. (2015). Implantación institucional del identificador orcid: un nuevo rol para las bibliotecas universitarias. Anuario ThinkEPI, 9, 132-134. https://doi.org/10.3145/thinkepi.2015.31 
FCT. (2013). Bibliometry - Frequently asked questions (FAQs) ORCID. Retrieved from https://www.fct.pt/apoios/unidades/avaliacoes/2013/ faqs.phtml.en

García-Peñalvo, F. J. (2018). Identidad digital como investigadores. La evidencia y la transparencia de la producción científica. Education in the Knowledge Society (EKS), 19(2), 7-28. https://doi.org/10.14201/ eks2018192728

Gasparyan, A. Y., Akazhanov, N. A., Voronov, A. A., \& Kitas, G. D. (2014). Systematic and Open Identification of Researchers and Authors: Focus on Open Researcher and Contributor ID. Journal of Korean Medical Science, 29(11), 1453-1456. https://doi.org/10.3346/ jkms.2014.29.11.1453

Gasparyan, A. Y., Yessirkepov, M., Gerasimov, A. N., Kostyukova, E. I., \& Kitas, G. D. (2016). Scientific author names: errors, corrections, and identity profiles. Biochemia Medica, 169-173. https://doi.org/10.11613/ BM.2016.017

Haak, L. L., Baker, D., Ginther, D. K., Gordon, G. J., Probus, M. A., Kannankutty, N., \& Weinberg, B. A. (2012). Standards and Infrastructure for Innovation Data Exchange. Science, 338(6104), 196-197. https:// doi.org/10.1126/science.1221840

Henderson, H., Johnson, R., \& Woodward, H. (2015). Institutional ORCID Implementation and Cost-Benefit Analysis Report. Retrieved from http://repository.jisc.ac.uk/id/eprint/6025

Horstmann, W., \& Brase, J. (2016). Libraries and Data - Paradigm Shifts and Challenges. Bibliothek Forschung und Praxis, 40(2), 273-277. https:// doi.org/10.1515/bfp-2016-0034

Klein, M., \& Van de Sompel, H. (2017). Discovering Scholarly Orphans Using ORCID. ArXiv:1703.09343 [Cs]. Retrieved from http://arxiv.org/ abs/1703.09343

Kraft, A., Dreyer, B., Löwe, P., \& Ziedorn, F. (2017). 14 Years of PID Services at the German National Library of Science and Technology (TIB): Connected Frameworks, Research Data and Lessons Learned from a National Research Library Perspective. Data Science Journal, 16, 36. https://doi.org/10.5334/dsj-2017-036

Lopes, A. L. (2019). Integrating a local CRIS with the PTCRIS synchronization ecosystem. Procedia Computer Science, 146, 166-172. https://doi. org/10.1016/j.procs.2019.01.091

Marín-Arraiza, P., \& Gumpenberger, C. (2019). ORCID Austria Consortium: Foundation and Perspectives. Figshare. https://doi. org/10.23640/07243.7728263 
Melchiorsen, P. (2019, February 26). The ORCID Danish Consortium Journey (Version 1). figshare. https://doi.org/10.23640/07243.7771163.v1 Ogungbeni, J. I., Obiamalu, A. R., Ssemambo, S., \& Bazibu, C. M. (2018). The roles of academic libraries in propagating open science: A qualitative literature review. Information Development, 34(2), 113-121. https:// doi.org/10.1177/0266666916678444

Piwowar, H. (2013). Value all research products. Nature, 493, 159.

Reimer, T. (2015). Your name is not good enough: introducing the ORCID researcher identifier at Imperial College London. Insights the UKSG Journal, 28(3), 76-82. https://doi.org/10.1629/uksg.268

Reimer, T. (2016). How to implement ORCID at a university? Retrieved from Open Access and Digital Scholarship Blog website: http://wwwf. imperial.ac.uk/blog/openaccess/2016/03/21/how-to-implement-orcid-at-a-university/

Rice, R., \& Southall, J. (2016). The data librarian's handbook. London: Facet Publishing.

Rodrigues, F. de A., \& Sant'Ana, R. C. G. (2018). Contextualização de conceitos teóricos no processo de coleta de dados de Redes Sociais Online. Informação \& Tecnologia (ITEC), 5(1), 18-36.

Tenopir, C., Sandusky, R. J., Allard, S., \& Birch, B. (2013). Academic librarians and research data services: preparation and attitudes. IFLA Journal, 39(1), 70-78. https://doi.org/10.1177/0340035212473089

Tenopir, C., Sandusky, R. J., Allard, S., \& Birch, B. (2014). Research data management services in academic research libraries and perceptions of librarians. Library \& Information Science Research, 36(2), 84-90. https:// doi.org/10.1016/j.lisr.2013.11.003

Thomas, Wm. J., Chen, B., \& Clement, G. (2015). ORCID Identifiers: Planned and Potential Uses by Associations, Publishers, and Librarians. The Serials Librarian, 68(1-4), 332-341. https://doi.org/10.1080/036152 6X.2015.1017713

Youtie, J., Carley, S., Porter, A. L., \& Shapira, P. (2017). Tracking researchers and their outputs: new insights from ORCIDs. Scientometrics, 113(1), 437-453. https://doi.org/10.1007/s11192-017-2473-0

1 ORCID member base: https://orcid.org/members

2 ISO Standard 27729:2012: https://www.iso.org/obp/ ui/\#iso:std:iso:27729:ed-1:v1:en

3 FOSTER Open Science Project: https://www.fosteropenscience.eu/

4 Crossref: https://www.crossref.org/ 
5 DataCite: https://datacite.org/

6 BASE: https://de.base-search.net/

7 Redalyc: https://www.redalyc.org/home.oa (interface only available in Spanish).

8 Europe PubMed Central: https://europepmc.org

9 The original paper also includes the task 'Assigning ORCID iDs to researchers'. However, ORCID identified it as a bad practice due to the high number of duplicated iDs and the lack of participation of the researcher. The currently offered option is the 'Create on demand' option, only if authorised by the researcher: http://members.orcid.org/ api/integrate/create-records

10 The original paper uses the word 'profile'. However, 'record' is preferred to avoid the confusion between online social networks and ORCID iD.

11 ORCID Best practices for research organisations: https://orcid.org/ content/best-practices-research-organizations

12 Austria, Belgium, Denmark, Finland, Germany, Greece, Italy, Netherlands, Norway, Portugal, Sweden and the United Kingdom.

13 Cyprus, Czech Republic, France, Hungary, Iceland, Ireland, Luxembourg, Poland, Spain and Switzerland.

14 Library's Welcome Kit for New Researcher at the Open University of Catalonia: https://bit.ly/2KOURpV

15 Information page about ORCID - University of Minho https://openaccess.sdum.uminho.pt/?p=3588 (only available in Portuguese).

16 ORCID DE: https://www.orcid-de.org/

17 TIB VIVO: https://vivo.tib.eu/fis/

18 RCAAP: https://www.rcaap.pt/ (Interface available in English and Portuguese)

19 UK ORCID Decision tree: https://ukorcidsupport.jisc.ac.uk/guidance/ decision-tree-2/

20 Greenwich Academic Literature Archive: https://gala.gre.ac.uk/

21 DMPbelgium: https://dmponline.be/

22 Leiden Open Variation Database: https://www.lovd.nl/

23 Scientometrics Working Group of the University of Vienna: https://bibliothek.univie.ac.at/bibliometrie/en/ag_szientometrie.html

24 e-Infrastructures Austria Plus: https://www.e-infrastructures.at/en/ home-english?set_language $=$ en

25 ORCID Austria: https://orcid.org/members/0010f00002JdacaAAB-tu-wien 26 ORCID-enabled systems: https://members.orcid.org/api/orcid-enabledsystems 